\section{Gamearte: uma poética de interação}

\section{RESUMO}

Gamearte é uma pesquisa que procura na linguagem do game eletrônico desenvolver uma poética artística digital interativa e de compartilhamento de espaços virtuais em instalações e na rede mundial de computadores, por meio da tecnologia da realidade virtual. A poética em desenvolvimento é marcada por uma reflexão onde o lúdico simula situações ou testa ruptura na desconstrução de outros modelos sociais. Modelagens físicas, mídias interativas, modificações randômicas, banco de dados iconográficos, mensagens subliminares e a inteligência artificial fazem parte dessa atmosfera virtual. Nesse sentido, o texto apresenta 0 desenvolvimento da pesquisa citando alguns teóricos importantes para o trabalho, tais como Ray Kurzweil, cientista e escritor que afirmou que em breve não será mais possível distinguir entre 0 pensamento humano e a capacidade das máquinas de processar e compreender os dados. Descreve, ainda, a história do game eletrônico, em função do seu desenvolvimento tecnológico como a aplicação da inteligência artificial e do design de suas interfaces gráficas e sensoriais.

\section{ABSTRACT}

This text discusses some issues related to electronic games and the simulation of reality as well as the history of their development and the role played by both artificial intelligence and the design of their interfaces towards a new poetics known as gameart.

\section{PALAVRAS-CHAVE (KEY WORDS)}

- Gamearte (Gameart)

- Tecnologia (Technology)

- Inteligência Artificial (Artificial intelligence)

\section{Mario Maciel}

Mestrando em Arte, Instituto de Artes, UnB

\section{Suzete Venturelli}

Doutora em Artes e Ciências da Arte, Universidade Sorbonne Paris 1.

Pesquisadora do CNPq, nível 1C,UnB. Coordenadora do GT Criações e Poéticas Digitais (Compós).

\section{Introdução}

ESTAMOS ENTRANDO no quadragésimo ano da história dos games eletrônicos e não há dúvida que eles provocaram um impacto importante na cultura visual contemporânea. O game eletrônico envolve a criatividade e a imaginação de designers, programadores, artistas, músicos e cineastas. Os jogos têm sido uma parte da cultura humana e os artistas muitas vezes criam jogos para ir além do simples entretenimento, tentando propor mudanças nas nossas percepções.

Alguns países do mundo realizaram exposições sobre esse fenômeno, tais como a exposição Game On, que ocorreu em 2002, na Barbican Gallery de Londres. Para o seu curador Conrad Bodman, essa exposição marcou o primeiro momento de reconhecimento de jogos para computador. A exposição mostrou que o assunto é interessante para um público diversificado e, também, demonstra que o jogo por computador é um fenômeno que, ao mesmo tempo, reflete e molda a nossa cultura.

$\mathrm{Na}$ análise dessa produção cultural verifica-se que ela está intimamente ligada à evolução tecnológica da computação, que passa pelos fundamentos conceituais do filósofo inglês Charles Babbage ${ }^{1}$ (1820), que concretizou a idéia de uma máquina de calcular tabelas aritméticas, o Engenho Diferencial. Por outro lado, é com o escritor EM Forster (EUA, 1909), que escreveu uma pequena história de ficção, The Machine Stops, na qual apresenta um mundo, semelhante ao nosso, onde a tecnologia provocou um profundo impacto nos indivíduos e na sociedade, que encontramos a primeira visão do que a tecnologia poderia provocar na cultura visual.

Mas é com Marshall McLuhan, que em 1964 publica o livro Understanding $\mathrm{Me}$ dia, no qual analisa a mídia a partir do mito 
de Narciso, como extensão do homem e, ainda, como metáfora, que vimos os primórdios da cultura visual analisada. A produção visual de massa influenciará a estética dos games.

$\mathrm{Na}$ construção de games eletrônicos são aplicadas as idéias do físico cibernético Gordon Pask (Londres, 1969), que ficou conhecido pela Conversation Theory, onde desenvolve um complexo sistema cibernético, semente de idéias arquiteturais cibernéti$\mathrm{cas}^{2}$, que são observáveis nas arquiteturas dos ambientes modelados no universo dos games, cujo nível simbólico não possui uma única matriz temática.

No nível de programação dos personagens destaca-se a aplicação dos avanços da inteligência artificial, que se caracteriza por marcar a maior diferença entre filme ou imagens animadas e imagens interativas ${ }^{3}$. $\mathrm{O}$ inventor da máquina inteligente, Ray Kurzweil (EUA, 2003), cientista e escritor, afirma que em breve não será mais possível distinguir entre o pensamento humano e a capacidade das máquinas de processar e compreender os dados. Segundo o autor estamos numa fase na qual a informática, a biotecnologia, a física quântica e a nanotecnologia $^{4}$ vão proporcionar avanços na área da inteligência artificial que, imitando os humanos, poderá responder com emoções, comunicar-se mediante a arte ou até chegar a novas idéias filosóficas. Essas idéias, invenções e conceitos brilham para todos aqueles que vêem no computador um meio de descoberta, de criatividade e de compartilhamento intelectual.

A exemplo dos games eletrônicos que ganham destaque com a possibilidade da criatividade interativa, descreve-se a seguir o desenvolvimento da tecnologia digital a partir da sua história.

\section{História dos games eletrônicos}

Como foi dito anteriormente, os videogames provocaram um impacto significativo na cultura contemporânea. Uma maneira diferente de percepção do espaço, do tempo e do próprio conceito de arte ${ }^{5}$, os jogos sempre despertaram curiosidade, e cada vez mais engenheiros, sociólogos, programadores, desenhistas, músicos trabalham na criação de jogos para cassinos, lazer, simulação, cooptação ideológica ou mesmo como poética artística.

A história do game eletrônico começa em 1962, há mais de 40 anos, com o computador PDP-1 num laboratório de pesquisa científica dos Estados Unidos da América (KING. 2002: 13). Em 1971, Nolan Brushnell desenvolveu o Computer Space, a primeira máquina de jogo comercial, com interface sensório-motora, que foi colocada em alguns bares do Silicon Valley. Essa máquina não fez muito sucesso, mas ajudou no desenvolvimento do design de interface das outras futuras máquinas de jogo, consoles como são também denominadas. Em 1972 (EUA) é lançado o Odyssey 100, o primeiro aparelho console originado do protótipo Brown Box, cuja capacidade de gerar gráficos era bastante precária, pois vinha acompanhado de placas de circuito externas (gigantes jumpers). Na medida em que o aparelho não tinha capacidade de gerar todos os pontos necessários da imagem, os jogadores eram obrigados a colocar cartões de plástico na tela da televisão (overlays) para poder gerar, por exemplo, o verde de um campo de futebol.

Em 1974, Nolan Bushnell e Ted Dabney montaram a empresa Atari exclusivamente para jogos eletrônicos. Eles inventaram um arcade ${ }^{6}$ chamado Pong uma espécie de ping-pong eletrônico, que ficou muito conhecido em todo o mundo. Paralelamente, surge o Space Invaders, jogo japonês criado pela Taito, que se torna um fenômeno de sucesso. Um dos maiores fãs desse jogo foi Satoshi Tajiri, criador do Pokémon. Em 1975 surge o primeiro console programável, o Zircon/Fairchild Channel F, que muda o conceito de games em função de seu sistema modular, no qual o usuário podia trocar os jogos por meio de cartuchos. Mas foi em 1978 que a empresa Bally lança 
o Professional Árcade, um console muito poderoso, que servia como um computador e utilizava cartuchos especiais para programação em Basic. Era mais computador que videogame.

Em 1979 surge o antecessor do Game Boy e do Game Gear, ou seja, o primeiro portátil, cujo sistema de console era muito parecido com os atuais (baterias, tela de cristal líquido, controles e botões no mesmo aparelho), entretanto só gerava gráficos em preto-e-branco.

No início da década de 80, a Mattel Eletronics, fabricante de brinquedos, desenvolve o Intellivision, segunda geração de videogame, cujo hardware possibilitava uma resolução gráfica e sonora bem melhor que os games existentes na época. A terceira geração começa em 1982, com o surgimento do ColecoVision, desenvolvido pela Conneticut Leather Company e Shigeru Miyamoto (o primeiro da Nintendo). O sucesso desse videogame vinha da conversão dos games conhecidos nos arcades para o sistema caseiro.

O primeiro console da história projetado para mostrar imagens vetoriais, ao invés de pixels, foi o GCE Vectrex, da Milton Bradley. Usando sistemas de cartões, possuía bons jogos e som excelente, entretanto a imagem era em PB. Esse videogame continha periféricos interessantes como óculos visualizador 3D e caneta óptica. Em 1983, nasce o computador mais console da história, cuja tarefa era ser um computador pessoal definitivo, desenvolvido pela Microsoft e a Ascii. Ele visualizava 16 cores simultâneas, utilizando a televisão como saída gráfica. O computador-console ficou famoso a partir de então. $\mathrm{O}$ maior produtor de jogos para o MSX foi a Konami, que desenvolveu os famosos Knightmare, Road Fighter e Kings Valley. Em 1986 a Microsoft deixou de desenvolver jogos para o MSX e a Ascii criou o MSX 2.0+, com mais memória e uma nova placa de vídeo. Nesse período surgem os videogames Sega Mega Drive e o Nintendo Super Famincon, que chegaram para substituir definitivamente o computa- dor-console.

Além do desenvolvimento do design dos consoles e do design de interface sensório-motora ${ }^{7}$, um dos aspectos mais importantes se refere ao estudo de personagens dos principais jogos que surgiram para as máquinas de videogames.

Segundo Steve Poole (2002), o desenho de um personagem para games é potencialmente uma arte profundamente difícil. A arte do desenho de personagens leva os jogadores a interagir com o game. Um personagem é a estrela do jogo e é a figura central que controla as ações nos ambientes. O personagem, nesse contexto, é bem diferente dos personagens de cinema e da telenovela. Ele pode ser escolhido individualmente e ter uma completa e sólida forma visual. Os personagens são inventados e completamente construídos desde o início do game. Historicamente, o primeiro personagem do videogame foi Pac-Man, criado em 1980. Antes dele, em games como Space Invader, citado anteriormente, os jogadores tinham controle de espaçonaves, armas e outros aparelhos mecânicos. Com Pac-Man, tudo mudou. De repente um jogador de Pac-Man estava controlando uma animação que podia comer algo.

Toru e Iwatani disseram que tiveram a idéia do personagem após comerem uma pizza. Pac-Man foi desenhado para ser um personagem possível, simples, sem qualquer outra informação gráfica, como olhos ou boca. Isto foi feito para despertar a imaginação do jogador. Um ano depois de PacMan, surge o primeiro videogame, Donkey Kong, de Shigeru Miyamoto (1981), contendo uma animação inteira com personagem humanóide (Poole 2002: 76-85).

Logo em seguida surge o personagem Mario. Seu estilo foi sendo ditado pela evolução tecnológica. Por exemplo, a baixa resolução oferecida pelo sistema de videogame não permitia que se projetasse um sistema com alta qualidade da imagem em função do pequeno número de pixels. Exemplo disso, Miyamoto criou um chapéu para o personagem porque na época 
não se podia simular cabelos para o game. No Japão existe grande influência estética do Mangá, história em quadrinhos e anime (desenho animado).

$\mathrm{Na}$ década de 90, foi lançado o jogo Myst criado pelos irmãos Robyn e Rand Miller e lançado pela Broderbund Software, no qual o principal personagem era um intelectual embaixador. $\mathrm{O}$ videogame passou a ser conhecido como o primeiro game desenvolvido para adultos. Segundo Steve Jonhson (2002: 157), Myst é fundamentalmente uma experiência 3D, mais próxima de um produto artístico do que do entretenimento, que provoca uma sensação no jogador de hipnose, de estranheza e de desorientação. Para o autor o prazer estético que o jogo proporciona pode ser observado em animações de projetos de arquitetura. Os ambientes tridimensionais são mais valorizados pelos irmãos Miller do que o estudo psicológico, ou mesmo realístico, dos personagens. O Myst III, lançado em Los Angeles na exposição 2000 de Entretenimento Eletrônico, foi considerado uma pedra fundamental no universo dos games.

Um bom personagem de videogame pode ser considerado aquele que congrega uma identidade, definida pela sua aparência, com movimentos que dêem prazer ao jogador. Os designers de personagens de última geração, como o Eike, Shadow of Memories (2000) de Konami, são realísticos e muitos são influenciados pela estética de animações japonesas.

Atualmente, apreciamos particularmente o videogame Final Fantasy ${ }^{8}$, pois representa uma geração de games com ambientes altamente realísticos, que aplicam o desenvolvimento científico-tecnológico da simulação e de modelagem física, assim como de inteligência artificial que controla e inicia as ações dos personagens e objetos virtuais. Essas ações, que podem ser interativas em tempo real, correspondem às animações, os diálogos que se estabelecem entre os objetos e personagens, com os jogadores e, no caso de sistemas de multiusuários, entre vários jogadores simultanea- mente. $\mathrm{O}$ game originou o filme do mesmo nome, no qual encontramos personagens com efeitos de simulação impressionantes (modelagem de pele, cabelos e expressões faciais) e com grande riqueza de detalhes. Não existem no filme imagens capturadas do real, todos os ambientes e atores virtuais foram gerados com modelagem computacional. Os personagens atuam como se estivessem na realidade. Um ponto interessante é que os character designers criaram diferentes personalidades para cada humano virtual, apesar de terem um modelo básico de construção da anatomia humana.

Outro aspecto importante no desenvolvimento de games computacionais são os criados para ambientes virtuais multijogadores, cujo sucesso vai depender inteiramente do tipo de sistema criado. Um dos mais famosos sistemas on-line multiusuário é Star Wars, criado pela LucasArts. Para o corrente ano existe uma grande expectativa em relação ao novo sistema que eles vão lançar, Star Wars Galaxies, que permitirá a participação simultânea de mais ou menos 300.000 jogadores. Empresas de entretenimento como a Sony, Eletronic Arts e Blizzard e Entertainment vêm investindo nos jogos multiusuários, os mais conhecidos são StarCraft, WarCraft e Diabolo II. O interessante nesses sistemas é que os jogadores trocam idéias, compartilham problemas e soluções cooperativas. A experiência experimentada é qualitativamente diferente, o mundo é dinâmico, pois está sempre em atividade e o jogo pode durar dias, semanas ou mesmo meses.

\section{Gamearte}

Gamearte é um projeto que procura na linguagem do game eletrônico desenvolver uma poética artística interativa e de compartilhamento de espaços virtuais em instalações e na rede mundial de computadores, por meio da tecnologia da realidade virtual. Como apresentado anteriormente, a pesquisa está apoiada em fundamentos teóri- 
cos oriundos da área da ciência da computação ${ }^{9}$, arte e comunicação especificamente aplicando desenvolvimentos tecnológicos da realidade virtual.

A poética em desenvolvimento é marcada por uma reflexão onde o lúdico simula situações ou testa ruptura na desconstrução de outros modelos sociais. Modelagens físicas, mídias interativas, modificações randômicas, banco de dados iconográficos, mensagens subliminares e a inteligência artificial fazem parte dessa atmosfera virtual.

Pode-se dizer que a revolução digital convenceu analistas do social, cientistas e filósofos de que estamos em um novo tempo da arte. ${ }^{10} \mathrm{~A}$ decifração do genoma e a replicação da vida sugerem que o ser humano já está imerso em uma era ciborguiana.

Era marcada pelas idéias de Marshall McLuhan ${ }^{11}$, canadense, professor de literatura inglesa que morreu no último dia de 1980, e antecipou o mundo da mídia em movimento. No ano seguinte começava a então revolução dos computadores pessoais e o conseqüente impacto da tecnologia digital. Essa sociedade competitiva e gananciosa obriga as pessoas a viverem enclausuradas $^{12}$, primeiro em casa, depois na escola, no trabalho ou até mesmo, em casos de transgressões consideradas inadmissíveis, numa autêntica prisão. Esses e outros fatores reforçam e justificam o sucesso dos videogames entre adolescentes e adultos. Essas ações acontecem em redes interativas. Todavia a morte e a banalização da violência estão presentes.

Quais são as mudanças que ocorrem no sujeito que interage com os games eletrônicos? Com as mutações tecnológicas, passamos do estado industrial ao hiperindustrial, que pretende integrar o mundo da cultura e o seu espírito no seio de um vasto sistema técnico-industrial, onde aparelhos de difusão cultural, signos e símbolos se condensam em muitas informações banais. Os receptores de televisão são, nesse contexto, terminais de teleação. Permitem que se assista aos programas, que se acione a distância variadas informações como com- prar e mandar mensagens. Talvez, exista atualmente uma sincronização geral de fluxos atemporais das consciências, que não cessa de se expandir. Nesse sentido, parece que estamos vivendo um processo de uniformização da informação que se relaciona com a mundialização dos sistemas de produção e difusão cultural.

Assim, para melhor analisar o contexto de surgimento do game eletrônico, estão sendo levadas em consideração as teorias de comunicação e cognitivas desenvolvidas principalmente pelo pensamento dos biólogos Francisco Varela e Humberto Maturana, do comunicólogo Armand Mattelart e do filósofo Félix Guattari. Este projeto, então, ao ter como referência teórica os pensamentos de Guattari, busca aplicar as idéias científicas dos biólogos nas reflexões que realizavam sobre as novas subjetividades estéticas provocadas pela informatização da sociedade e seus processos de criação com as máquinas, que vêm se firmando como máquinas autopoiéticas.

O estudo teórico dessas idéias que enfocam a relação do sujeito e da máquina na contemporaneidade possivelmente contribuirá para que se compreenda melhor as características do game eletrônico nos aspectos estéticos-éticos-políticos. Além disso, pretende-se analisar, também, os games eletrônicos, criados para a rede mundial dos computadores, que envolvem pessoas de culturas diferentes, que se comunicam e interagem em espaços virtuais multiusuários, assim como produzir gamearte, como poética artística.

Para tanto, pretende-se no decorrer do desenvolvimento da pesquisa: 1 . analisar a criatividade social representada, neste projeto, pelos games eletrônicos desenvolvidos em culturas diferentes para verificar o enquadramento ideológico existente nos roteiros; 2 . verificar o envolvimento do sujeito com as interfaces gráficas e/ou sensório-motoras, desenvolvidas principalmente a partir das tecnologias da Realidade Virtual; 3. analisar os paradigmas estéticos-éticos-políticos nos ambientes virtuais dos ga- 
mes; 4. verificar o estado da arte da tecnologia computacional no desenvolvimento da simulação do movimento do humano virtual e modelagem física da realidade; 5 . criar obras artísticas contendo simulações de movimentos de humanos virtuais e interação do sujeito com um roteiro estéticoético-político.

Para a criação do trabalho poético estão sendo desenvolvidos alguns roteiros, experimentais, sobre questões estéticas-éticas-políticas de caráter crítico e de interação com indivíduos de culturas diferentes. Para tanto, pretende-se buscar entender quais são os valores estéticos-éticos-políticos difundidos pelas mídias locais para compará-los com os valores ditos universais e/ou tradicionais. Nesse sentido, as análises de Armand Mattelart serão fundamentais na medida em que ele é especialista em comunicação e analisa problemas que existem na atualidade em relação aos poderes econômicos que difundem idéias e opiniões manipuladoras.

\section{Produções realizadas}

Foram desenvolvidos dois trabalhos experimentais, BsB Virtual e Hubbub. Ambos aplicam algumas noções de inteligência artificial na definição dos comportamentos das personagens que habitam o gamearte. Os personagens, não são agentes ${ }^{13}$ autômatos, pois não possuem vida própria, mas são personagens que reagem às ações do usuário de forma inteligente, como, por exemplo, procuram mostrar um tipo de personalidade eletrônica, que pode ser percebida pela capacidade de tomar decisões sensíveis de forma autônoma, mas controlada pela máquina.

Os personagens são controlados por um programa computacional, desenvolvido com linguagem de programação que controla, por sua vez, as animações incorporadas a eles, tais como andar simulando um ser humano ou um carro. Assim como um videogame procura-se evidenciar a re- presentação do corpo humano realístico. Mas os seus ambientes revelam outras propostas de interação com o usuário. BsB Virtual propõe um espaço tridimensional representando a cidade de Brasília, no qual podem ser acionadas imagens animadas contendo fotografias de personagens históricos, dois ambientes estão conectados através de um portal que deve ser ultrapassado pelo usuário. No primeiro ambiente, o agente é um carro da época da construção de Brasília, que se desloca se assim for desejado. O segundo ambiente, composto por fotografias da cidade, o agente é uma bengala que caminha como um ser humano.

O gamearte Hubbub usa recursos do design de videogame, como, por exemplo, personagens semelhantes aos cavaleiros feudais. Esses personagens levam o usuário a percorrer ambientes ruidosos que são preenchidos por imagens do cotidiano atual. Essa fumaça se espalha na medida em que existe interação e o tempo passa. Modelagem física de sangue preenche os ambientes constantemente, sem cessar. No momento, os personagens existentes, embora possuam inteligência em estado primitivo, provocam no usuário uma reação de reflexo provocado pelos movimentos de deslocamento, rotação, imersão e cognitivos na medida em que existem interações acessíveis pela interface gráfica e via teclado, mouse e/ou joystick.

Nesse contexto, buscou-se trabalhar com o conceito de "virtus", da inteligência, para provocar ações e reações entre agentes e usuários, pois, dessa maneira, o usuário não desista do ambiente em que está, sem compreender o agente desse mundo; procurou-se, ainda, despertar o desejo no sujeito que interge de viver certas situações que não podem ser vividas na realidade (desejo de uma outra vida, onde podemos ser outro); e, como última característica, tentou-se, por meio das imagens, trazer o usuário a um estado de pulsão, de fascinação pela forma sensível, pela aparência, assim como evidenciado em jogos computacionais. Procurou-se, ainda, de certo modo, 
induzir a idéia de vida das formas que podem até morrer, lembrando, assim, o movimento da vida.

Os comportamentos tomam por base a técnica de cinemática direta que permite a obtenção de movimentos complexos dos corpos dos agentes humanóides. O modelo humano é um conjunto de objetos que são agrupados com encaixes de junções. Todos os movimentos podem ser representados por equações da cinemática, que estabelece as relações entre, por exemplo, posição, velocidade, aceleração, rotação e translação. Para as modificações dos estados dos comportamentos, foram definidos cinco eventos, três deles dependem de uma variável relacionada às ações das personagens.

A poética que está sendo pesquisada tomando por base uma produção cultural, mais próxima de uma subcultura, propõe trabalhos elaborados mais para desconcertar do que para agradar o público. O público interessado é aquele que também se interessa por história em quadrinhos (HQ), animações, jogos de videogames, literatura e cinema de ficção. Nesse sentido, a produção atual está claramente influenciada pela pop arte, cuja imagem vai ao encontro de uma cultura mais popular e menos especializada em arte contemporânea. Talvez, a ascensão de uma subcultura dê ao novo meio emergente mais legitimidade entre os especialistas da cultura dominante. Podese dizer que nesse meio a subcultura produz as inovações, enquanto que a cultura dominante se apropria de resultados interessantes para vendê-los para um público maior (Johnson 2001: 164).

Os visionários rebeldes, citados no início do texto, buscavam com seus estudos atingir um grande público de massa. Talvez seja esse o caminho de obras computacionais, pois elas podem ser veiculadas em interessantes meios como as redes de computadores e ainda ser um sistema de multiusuário, com participações simultâneas de inúmeras pessoas. Esse tipo de obra pode ser considerado como um sistema que permite sintetizar uma idéia, para que o todo seja visto, e se opõe à tendência analista que considera as produções digitais, principalmente as veiculadas na rede Internet, como participante da consciência fragmentada da era digital e de idéias que se deslocam sem rumo pela infoesfera •

\section{Notas}

1 São importantes para o assunto os estudos do engenheiro elétrico e inventor Vannevar Bush (EUA, 1945), autor do ensaio As We May Think, que contém a semente do que denominamos de hipertexto e inspirou o cientista Ted Nelson a elaborar o projeto Xanadu que continha noção de um ambiente computacional multimídia; o matemático Norbert Wiener (EUA, 1950), o primeiro a pensar sobre cibernética, que publicou Cibernetics, or Control and Communication in the Animal and Machine, onde imaginou a futura sociedade baseada na informação como utópica sem barreiras; JCR Licklider (EUA, 1960), professor do Massachusets Institute of Tecnology (MIT), contribuiu para 0 desenvolvimento de ambientes hipertextuais de interação entre sujeito máquina para as redes mundiais de computadores (Spiller 1999: 47); o cientista visionário Douglas Engelbart (EUA, 1962), que desenvolveu tecnologias de teleconferência e informação em Augment-

ing Human Intelect, no qual descreve a sua versão de hipermídia interativa.

2 A cibernética estuda as comunicações e os sistemas de controle nos organismos vivos e nas máquinas.

3 Na atualidade, existe muito interesse pelo termo interatividade em função do modelo que ele representa, capaz de gerar uma quantidade quase infinita de percursos diferentes, ao se remeter ao virtual.

4 Nanotecnologia agrupa o conjunto de teorias, regras, mecanismos ou realizações que visam à produção e manipulação de objetos cujo tamanho é comparável ao das moléculas e dos átomos.

5 Pode-se dizer que o pixel, o menor elemento da imagem digital, revela uma característica da minimal arte.

6 Arcade é uma máquina especifica para rodar um determinado jogo. 
7 Interface sujeito/máquina que permite a troca de informações. As interações, por exemplo, ocorrem através das mãos, movimentos do corpo, comandos sonoros.

8 Criado pelo pessoal da $\mathrm{RD}$ (Research and Developement).

9 Da ciência da computação a pesquisa está se apoiando na tecnologia da realidade virtual e inteligência artificial.

10 Lucia Santaella é professora titular da PUC/SP. Publicou Imagem, Semiótica, Cognição e Mídias em co-autoria com Winfried Noth.

11 Marshall McLuhan escreveu Understanding Media, em 1964.

12 Deleuze cita Foucault e a sociedade de controle.

130 conceito original de agente é atribuído ao software Advice Taker de John McCarthy de 1950. Entretanto, o termo entrou no vocabulário da informática em 1989 com o lançamento do vídeo Knowledge Navigator da Apple. Esse vídeo apresentada um solicito personagem ao lado de um Power-Book que auxiliava um professor em sua pesquisa. A metáfora é de um mordomo, ou seja, um infomordomo que simulava um ser humano (STEVEN, 2001: 129-132). Surge, assim, o agente antropomorfo, seguindo a tradição iniciada pela Macintosh que lança interfaces gráficas completamente preenchidas com metáforas visuais, tais como as pastas, os armários, 0 mouse etc. Além das metáforas, começou-se a imaginar os computadores como ser humano, que soubessem falar, escrever, que fossem perceptivos e prestativos. Segundo Steven Johnson, nesse contexto, o agente antropo-morfo é uma entidade, com aparência de um indivíduo, com certa personalidade, preso no monitor de vídeo, que se comunica com o seu usuário conectado. Os agentes podem, ainda, assumir diferentes formas, como de caixa de diálogo ou mesmo de trabalharem por detrás da interface, sem serem vistos. Alguns são do tipo espiões, ou seja, misantropos e sicofantas, ficando para sempre instalados no nosso computador pessoal, observando nosso comportamento e ajudando, se for o caso, nas tarefas. Enfim, pode-se dizer que os agentes já possuem uma certa capacidade cognitiva, são inteligentes e estão modificando as interfaces entre sujeito/máquina. Podem ser classificados como agente social ou pessoal, podendo se deslocar entre diferentes máquinas e/ou se instalar em uma máquina pessoal.

\section{Referências}

DAMER, Bruce. Avatars: exploring and building virtual worlds on the Internet. Berkeley: Peachpit Press; 1998.

DELEUZE, Gilles e GUATTARI, Félix. Mille Plateaux: capitalisme et schizophrénie. Paris: Lês Editions de Minuit, 1980.

JOHNSON, Steven. Cultura da interface: como o computador transforma nossa maneira de criar e comunicar. Rio de Janeiro: Editora Zahar, 2001.

KING, Lucien. Game On: the history and culture of videogames. London: Laurence King Publishing Ltd, 2002.

MATTELART, Michèle et Armand. História das teorias da comunicação. São Paulo: Loyola. 2000.

MATURANA, Humberto e VARELA, Francisco. Autopoiesis and Cognition. Boston: D. Reidel, 1980.

PLANT, Sadie. Muther Digital: o feminino e as novas tecnologias. Rio de Janeiro: Rosa dos Tempos. 1999.

POOLE, Steve. 'Character Forming'. In: Game On: the history and culture of videogames, King, Lucien. London: Laurence King Publishing Ltd, 2002, p. 76-85.

SPILLER, Neil. Cyber Reader: critical writtings for digital era. Londres: Phaidon, 1999. 